\title{
BMJ Open Inequalities in ventilation tube insertion procedures between Aboriginal and non-Aboriginal children in New South Wales, Australia: a data linkage study
}

\author{
Kathleen Falster, ${ }^{1,2,3}$ Deborah Randall, ${ }^{3}$ Emily Banks, ${ }^{1,2}$ Sandra Eades, ${ }^{4}$ \\ Hasantha Gunasekera, ${ }^{5}$ Jennifer Reath, ${ }^{6}$ Louisa Jorm ${ }^{3}$
}

To cite: Falster K, Randall D, Banks $\mathrm{E}$, et al. Inequalities in ventilation tube insertion procedures between

Aboriginal and non-Aboriginal children in New South Wales, Australia: a data linkage study. BMJ Open 2013:3:e003807. doi:10.1136/bmjopen-2013003807

- Prepublication history and additional material for this paper is available online. To view these files please visit the journal online (http://dx.doi.org/10.1136/ bmjopen-2013-003807).

Received 14 August 2013 Revised 16 October 2013 Accepted 17 October 2013

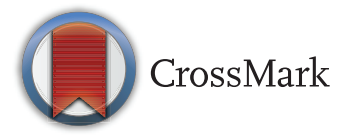

For numbered affiliations see end of article.

Correspondence to Dr Kathleen Falster; kathleen.falster@anu.edu.au

\section{ABSTRACT}

Objectives: Australian Aboriginal children experience earlier, more frequent and more severe otitis media, particularly in remote communities, than non-Aboriginal children. Insertion of ventilation tubes is the main surgical procedure for otitis media. Our aim was to quantify inequalities in ventilation tube insertion (VTI) procedures between Australian Aboriginal and non-Aboriginal children, and to explore the influence of birth characteristics, socioeconomic background and geographical remoteness on this inequality.

Design: Retrospective cohort study using linked hospital and mortality data from July 2000 to December 2008.

Setting and participants: A whole-of-population cohort of 653550 children (16 831 Aboriginal and 636719 non-Aboriginal) born in a New South Wales hospital between 1 July 2000 and 31 December 2007 was included in the analysis.

Outcome measure: First VTI procedure.

Results: VTI rates were lower in Aboriginal compared with non-Aboriginal children (incidence rate (IR), 4.3/ 1000 person-years; $95 \% \mathrm{Cl} 3.8$ to 4.8 vs IR $5.8 / 1000$ person-years; $95 \% \mathrm{Cl} 5.7$ to 5.8 ). Overall, Aboriginal children were $28 \%$ less likely than non-Aboriginal children to have ventilation tubes inserted (ageadjusted and sex-adjusted rate ratios (RRs) 0.72; 95\% $\mathrm{Cl} 0.64$ to 0.80 ). After adjusting additionally for geographical remoteness, Aboriginal children were $19 \%$ less likely to have ventilation tubes inserted (ageadjusted and sex-adjusted RR $0.81 ; 95 \% \mathrm{Cl} 0.73$ to 0.91). After adjusting separately for private patient/ health insurance status and area socioeconomic status, there was no significant difference (age-adjusted and sex-adjusted RR 0.96; 95\% Cl 0.86 to 1.08 and RR $0.93 ; 95 \% \mathrm{Cl} 0.83$ to 1.04 , respectively). In the fully adjusted model, there were no significant differences in VTI rates between Aboriginal and non-Aboriginal children (RR 1.06; 95\% Cl 0.94 to 1.19).

Conclusions: Despite a much higher prevalence of otitis media, Aboriginal children were less likely to receive VTI procedures than their non-Aboriginal counterparts; this inequality was largely explained by differences in socioeconomic status and geographical remoteness.

\section{Strengths and limitations of this study}

- Use of a whole-of-population cohort maximised statistical power and minimised selection bias associated with participant selection.

- The number of Aboriginal children in the cohort is likely to be underestimated because Aboriginal status is under-reported in the hospital data.

- We were unable to ascertain an individual's clinical need for procedures from the hospital data.

\section{INTRODUCTION}

Australian Aboriginal children living in remote communities experience an overwhelming burden of otitis media. ${ }^{1}$ A study conducted in remote northern and central Australian communities in 2001 found that $91 \%$ of the 709 participating Aboriginal children aged 6-30 months had otitis media. ${ }^{2}$ Of serious concern is the estimated $11-15 \%$ of Aboriginal children in these communities who suffer from chronic suppurative otitis media, ${ }^{2}{ }^{3}$ which are among the highest prevalence estimates reported internationally and constitute a 'massive public health problem' by WHO standards. ${ }^{4}$ There is considerable variation in the prevalence of otitis media between Aboriginal communities throughout Australia, ${ }^{2}$ however, and little is known about the magnitude of the problem among children living in urban areas ${ }^{5}$ or the eastern states of Australia where the majority of the Aboriginal population live. ${ }^{6}$

Despite the clinically apparent differences in the burden of otitis media between Aboriginal and non-Aboriginal children, there is limited quantitative evidence of this inequality. National health surveys indicate that Aboriginal children experience ear disease and/or hearing loss more than three times as often as their non-Aboriginal counterparts $(10 \%$ vs $3 \%){ }^{7}$ However, it is not possible to 
ascertain from these data how much can be directly attributed to otitis media. ${ }^{7}$ In the mid-1990s, a northern Australian cohort study found that Aboriginal infants from a remote area suffered otitis media and its complications more often and earlier in life than non-Aboriginal infants; however, the study sample was small and the non-Aboriginal comparison group lived in the city. ${ }^{8}$ Another source of evidence is the Bettering the Evaluation And Care of Health (BEACH) data, derived from ongoing surveys of primary care consultations nationally. These data suggest that Aboriginal children present for otitis media more frequently than non-Aboriginal children (9.8 vs $7.3 / 100$ consultations) and that their otitis media is more often severe. ${ }^{9}$ The BEACH data, however, do not capture undiagnosed cases of otitis media in the community. The exact reasons underlying the inequality in otitis media prevalence between Aboriginal and non-Aboriginal children are not fully understood, although they are likely to be multifactorial and interrelated. Some risk factors for otitis media that remain common in many Aboriginal families include large numbers of children living in the same household, ${ }^{10}{ }^{11}$ recent ear infections among family members, ${ }^{12}{ }^{13}$ poor housing quality ${ }_{1}^{14}$ high nasal pathogen loads ${ }^{15}{ }^{16}$ and infant bottle feeding. ${ }^{13}$

An equally important consideration is whether those Aboriginal children who suffer otitis media are receiving appropriate and equitable healthcare. Although limited data are available on otitis media management in primary care, surgical procedures are well captured in hospital data. ${ }^{17}$ Insertion of ventilation tubes is one of the management options recommended for children with recurrent acute otitis media or persistent bilateral otitis media with effusion and hearing loss. ${ }^{18} 19$ These procedures drain fluid from the middle ear and/or provide prolonged aeration to the middle ear via the ventilation tube. ${ }^{18} 20$ The use of these procedures is somewhat controversial because-despite evidence of short-term improvements in hearing and reduced infection rates-there is limited evidence regarding their long-term benefits and when they are best indicated. ${ }^{21} 22$ Furthermore, guidelines regarding ventilation tube insertion (VTI) are more stringent in non-Aboriginal compared with Aboriginal children. ${ }^{18}$ The only previously published study of VTI procedures in Aboriginal compared with non-Aboriginal children, to our knowledge, reported lower procedure rates in Aboriginal children in Western Australia. ${ }^{23}$ This study did not investigate factors underlying this inequality. ${ }^{23}$

New South Wales (NSW) is the state with the largest and most urbanised Aboriginal population in Australia. Furthermore, its large population is distributed across major cities and regional and remote areas. In this study, we used linked hospital and mortality data for NSW to quantify inequalities in first VTI procedures between Aboriginal and non-Aboriginal children and to investigate the influence of birth characteristics, socioeconomic background and geographical remoteness on this inequality.

\section{METHODS}

\section{Study design}

This study was a retrospective cohort design using linked hospital and mortality data.

\section{Data sources}

The NSW Admitted Patients Data Collection (APDC) includes records of all hospital separations (discharges, transfers and deaths) from all public, private, psychiatric and repatriation hospitals in NSW, as well as public multipurpose services, private day procedure centres and public nursing homes. Each record represents an episode of care that ends when a patient is transferred to another type of care, discharged from hospital or dies. The patient demographics and multiple diagnoses and procedures are recorded for each separation. Diagnoses are coded according to the Australian Modification of the International Statistical Classification of Diseases and Related Problems, 10th Revision (ICD-10-AM) ${ }^{24}$ and procedures according to the Australian Classification of Health Interventions. ${ }^{24}$ The NSW Register of Births, Deaths and Marriages (RBDM) captures details of all deaths registered in the state.

\section{Probabilistic record linkage}

The APDC from 1 July 2000 to 31 December 2008 was linked to the RBDM from 1 July 2000 to 31 December 2009. Personal identifiers (including full names, sex, date of birth and address) from the datasets were linked using probabilistic methods by the Centre for Health Record Linkage. ${ }^{25}$ Researchers were supplied with de-identified APDC and RBDM data. These data were merged using a project-specific unique person number.

\section{Setting}

NSW covers an area of approximately $810000 \mathrm{~km}^{2}$ and is Australia's most populous state. In 2006, NSW had approximately 6.8 million residents, of whom $2.2 \%$ (almost 150000 ) were recorded as Aboriginal and/or Torres Strait Islander people (henceforth referred to as 'Aboriginal' because Torres Strait Islander people account for only $0.1 \%$ of the NSW population).$^{26}$ In $2006,73 \%$ of the total NSW population lived in a major city compared with $43 \%$ of the NSW Aboriginal population. ${ }^{26}$

\section{Participants}

The linked data were used to define a cohort of children who were NSW residents and were born in a public or private hospital in NSW between 1 July 2000 and 31 December 2007. Records in the APDC with 'live born infant' (Z38 ICD-10-AM codes) included in a diagnosis field or a date of birth that was greater than or equal to the admission date and less than or equal to the separation date were considered as birth admissions. A total of 653681 children met these inclusion criteria. Children were excluded if their sex was coded as indeterminate or missing or there were discrepancies in their date of birth, admission and/or separation date on their birth record (6 
Aboriginal and 125 non-Aboriginal). A similar proportion of excluded children received ventilation tubes (2.3\%) compared with the study cohort $(2.6 \%)$. The final study cohort included 653550 children (16 831Aboriginal and 636719 non-Aboriginal).

\section{Analysis variables}

The study outcome was the first VTI procedure (unilateral or bilateral, coded as $41632-00$ and $41632-01$, respectively) recorded in the APDC during the study period.

The primary explanatory variable of interest was Aboriginal status. Although recording of Aboriginal status has improved over time, it is known to be underrecorded in the NSW public hospital data. ${ }^{27}$ Although probabilistic linkage offers the opportunity to improve ascertainment of Aboriginal status for individuals by using their entire admission history, we used Aboriginal status at birth to avoid introducing differential misclassification bias whereby sicker children who are admitted to hospital more frequently would have more opportunity to be recorded as Aboriginal, either correctly or through keystroke error. In the absence of an external source of Aboriginal status for validation, we conducted sensitivity analyses using two alternative definitions: (1) Aboriginal on the most recent hospital record and (2) Aboriginal on any hospital record.

With the exception of age, all potential confounding and mediating variables were based on the birth record to minimise differential misclassification bias, whereby children who were hospitalised more frequently during the study had more opportunities to update their status than children who had fewer hospitalisations. Age and sex were included as confounding variables in multivariate analyses and the following were included as mediating variables: low birth weight, defined as less than $2500 \mathrm{~g}$; prematurity at birth, defined as less than 37 weeks' gestational age; private patient or health insurance status; geographical remoteness included major city and inner regional, outer regional and remote/very remote categories based on the Accessibility/ Remoteness Index of Australia (ARIA +$)^{28}$; area-level socioeconomic status, based on the Australian Bureau of Statistics' Socio-Economic Index for Areas (SEIFA) Index of Relative Social Advantage and Disadvantage (2006 version) ${ }^{29}$ SEIFA scores were classified into population quintile groups for the analysis. Both ARIA+ and SEIFA categories were assigned to individuals based on their statistical local area of residence. Among children who received a VTI procedure, the percentages of children who changed status on key variables between birth and VTI admission were $6 \%$ for geographical remoteness, $11 \%$ for area-level socioeconomic status and $32 \%$ for private patient/health insurance status.

\section{Statistical analysis}

Person-years were accrued from the date of birth and terminated at the first of: the first VTI, date of death, 31
December 2008 or the date of a child's eighth birthday. Kaplan-Meier methods were used to assess time to first VTI procedure since birth and the log rank test for equality of survivor functions was used to assess the difference in time to first procedure between Aboriginal and non-Aboriginal children. Incidence rates (IRs) for first VTI procedures per 1000 person-years were calculated by dividing the number of first VTI procedures by the personyears accumulated for Aboriginal and non-Aboriginal children and for each confounding and mediating variable, and multiplying by 1000 . CIs at the $95 \%$ confidence level were calculated assuming a Poisson distribution of the first VTI procedures. Poisson regression was used to estimate rate ratios (RRs) with 95\% CIs to compare first VTI procedures between Aboriginal and non-Aboriginal children, including adjustment for potentially confounding and mediating variables. Covariates were entered into the model if they had a $\mathrm{p}$ value less than 0.10 in the univariate analysis. The forward stepwise method was used to build the multivariate models, using the log-likelihood ratio statistic to assess contribution to the model. $\mathrm{p}$ Values less than 0.05 were considered statistically significant. An interaction term for age and Aboriginality was tested and included in one of the models. Analyses were performed in SAS V.9.3 (SAS Institute, Cary, North Carolina, USA).

\section{Results}

Of the 16831 Aboriginal children in the cohort, 310 received their first VTI procedure during 72663 personyears of follow-up, giving a procedure rate of $4.3(95 \% \mathrm{CI}$ 3.8 to 4.8 )/1000 person-years (table 1 ). Of the 636719 non-Aboriginal children, 16 781received their first VTI procedure during 2916105 person-years of follow-up, which equals a procedure rate of 5.8 (95\% CI 5.7 to 5.8)/ 1000 person-years (table 1). The mean duration of follow-up in the cohort was 4.6 years (SD, 2.2 years) and the median number of hospital admissions was one (IQR, $1-2)$. On average, Aboriginal children were 3.1 years (SD, $1.6)$ and non-Aboriginal children were 2.9 years $(\mathrm{SD}, 1.5)$ when they had their first ventilation tubes inserted. Procedure rates were lower among Aboriginal compared with non-Aboriginal children aged $0-1$ years (IR 3.2; $95 \%$ CI 2.6 to 3.8 vs IR $5.3 ; 95 \%$ CI 5.1 to 5.4 ) and $2-3$ years (IR 5.4; $95 \%$ CI 4.4 to 6.4 vs IR $7.1 ; 95 \%$ CI 6.9 to 7.3 ); however, there were no significant differences among older children (figure 1). Figure 2 shows that the time from birth to first VTI was significantly greater in Aboriginal compared with non-Aboriginal children in the cohort ( $\mathrm{p}<0.001$; figure 2).

Aboriginal children were $28 \%$ less likely to have ventilation tubes inserted than non-Aboriginal children in the cohort (RR 0.72; 95\% CI 0.64 to 0.80; table 2, model 1). This estimate of inequality remained the same after adjustment for age and sex (table 2, model 2) and changed slightly after accounting for low birth weight or prematurity in the model (age and sex adjusted RR $0.71 ; 95 \%$ CI 0.63 to 0.79 for both variables; table 2 , models 3 and 4 ). After taking age, sex and remoteness into account, 
Table 1 Birth characteristics and first VTI procedure rates in a cohort of children in New South Wales, Australia, 2000-2008

\begin{tabular}{|c|c|c|c|c|c|c|c|c|c|c|c|c|}
\hline & \multicolumn{2}{|c|}{ Non-Aboriginal } & \multicolumn{2}{|c|}{ Aboriginal } & \multicolumn{4}{|c|}{ Non-Aboriginal } & \multicolumn{4}{|c|}{ Aboriginal } \\
\hline & $\mathbf{N}$ & $\begin{array}{l}\text { Per } \\
\text { cent }\end{array}$ & $\mathbf{N}$ & $\begin{array}{l}\text { Per } \\
\text { cent }\end{array}$ & $\begin{array}{l}\text { Number of } \\
\text { VTI }\end{array}$ & Person-years & $\mathbf{I R}^{*}$ & $95 \% \mathrm{Cl}$ & $\begin{array}{l}\text { No. } \\
\text { VTI }\end{array}$ & Person-years & $\mathbf{I R}^{*}$ & $95 \% \mathrm{Cl}$ \\
\hline Total & 636719 & 100 & 16831 & 100 & 16781 & 2916105 & 5.8 & 5.7 to 5.8 & 310 & 72663 & 4.3 & 3.8 to 4.8 \\
\hline \multicolumn{13}{|l|}{ Sex } \\
\hline Female & 308579 & 48 & 8221 & 49 & 6395 & 1418529 & 4.5 & 4.4 to 4.6 & 120 & 35655 & 3.4 & 2.8 to 4.0 \\
\hline Male & 328140 & 52 & 8610 & 51 & 10386 & 1497577 & 6.9 & 6.8 to 7.1 & 190 & 37008 & 5.1 & 4.4 to 5.9 \\
\hline \multicolumn{13}{|c|}{ Low birth weight $(<2500 \mathrm{~g})$} \\
\hline No & 614308 & 96 & 15763 & 94 & 16051 & 2820959 & 5.7 & 5.6 to 5.8 & 282 & 68483 & 4.1 & 3.7 to 4.6 \\
\hline Yes & 22411 & 4 & 1068 & 6 & 730 & 95147 & 7.7 & 7.1 to 8.3 & 28 & 4179 & 6.7 & 4.5 to 9.7 \\
\hline \multicolumn{13}{|c|}{ Premature birth (<37 weeks' gestational age) } \\
\hline No & 599380 & 94 & 15245 & 91 & 15542 & 2754484 & 5.6 & 5.6 to 5.7 & 272 & 66331 & 4.1 & 3.6 to 4.6 \\
\hline Yes & 37339 & 6 & 1586 & 9 & 1239 & 161621 & 7.7 & 7.2 to 8.1 & 38 & 6332 & 6.0 & 4.2 to 8.2 \\
\hline \multicolumn{13}{|c|}{ Private patient or private health insurance } \\
\hline No & 447817 & 70 & 16605 & 99 & 8661 & 2072256 & 4.2 & 4.1 to 4.3 & 303 & 71818 & 4.2 & 3.8 to 4.7 \\
\hline Yes & 188902 & 30 & 226 & 1 & 8120 & 843850 & 9.6 & 9.4 to 9.8 & 7 & 845 & 8.3 & 3.3 to 17.1 \\
\hline \multicolumn{13}{|l|}{ Remoteness (ARIA+) } \\
\hline Major city & 421287 & 66 & 4945 & 29 & 11553 & 1917085 & 6.0 & 5.9 to 6.1 & 101 & 21171 & 4.8 & 3.9 to 5.8 \\
\hline Inner regional & 158346 & 25 & 5815 & 35 & 4264 & 731689 & 5.8 & 5.7 to 6.0 & 125 & 24708 & 5.1 & 4.2 to 6.0 \\
\hline Outer regional & 52032 & 8 & 4226 & 25 & 871 & 242980 & 3.6 & 3.4 to 3.8 & 69 & 18328 & 3.8 & 2.9 to 4.8 \\
\hline Remote/very remote & 5054 & 1 & 1845 & 11 & 93 & 24351 & 3.8 & 3.1 to 4.7 & 15 & 8456 & 1.8 & 1.0 to 2.9 \\
\hline \multicolumn{13}{|c|}{ Area socioeconomic status $†$} \\
\hline $\begin{array}{l}\text { First quintile (most } \\
\text { disadvantaged) }\end{array}$ & 120604 & 19 & 8234 & 49 & 1976 & 560732 & 3.5 & 3.4 to 3.7 & 130 & 36376 & 3.6 & 3.0 to 4.2 \\
\hline Second quintile & 138822 & 22 & 4412 & 26 & 3277 & 638688 & 5.1 & 5.0 to 5.3 & 102 & 18715 & 5.5 & 4.4 to 6.6 \\
\hline Third quintile & 128511 & 20 & 2736 & 16 & 2960 & 592752 & 5.0 & 4.8 to 5.2 & 52 & 11635 & 4.5 & 3.3 to 5.9 \\
\hline Fourth quintile & 130018 & 20 & 1146 & 7 & 3412 & 592662 & 5.8 & 5.6 to 6.0 & 18 & 4816 & 3.7 & 2.2 to 5.9 \\
\hline $\begin{array}{l}\text { Fifth quintile (least } \\
\text { disadvantaged) }\end{array}$ & 118764 & 19 & 303 & 2 & 5156 & 531272 & 9.7 & 9.4 to 10.0 & 8 & 1121 & 7.1 & 3.1 to 14.1 \\
\hline
\end{tabular}

${ }^{*}$ Per 1000 person-years.

TSEIFA Index of Relative Socio-Economic Advantage and Disadvantage based on the child's statistical local area of residence at birth.

ARIA+, Accessibility/Remoteness Index of Australia; IR, incidence rate; SEIFA, socio-economic indices for Areas; VTI, ventilation tube insertion. 
Aboriginal children were $19 \%$ less likely to have ventilation tubes inserted (RR 0.81; 95\% CI 0.73 to 0.91 ; model 6). After adjustment for age, sex and private patient/health insurance status or area socioeconomic status, procedure rates were no longer significantly different between Aboriginal and non-Aboriginal children (RR 0.96; 95\% CI 0.86 to 1.08 ; table 2 , model 5 and RR $0.93 ; 95 \%$ CI 0.83 to 1.04; table 2, model 7, respectively). In the fully adjusted model, there was no significant difference in VTI procedure rates between Aboriginal and non-Aboriginal children (RR $1.06 ; 95 \%$ CI 0.94 to 1.19 , table 2, model 8).

Table 3 presents RRs for significant covariates in the final adjusted model (model 8). Among all children, VTI procedures were $36 \%$ more likely in children aged 2-3 years and $17 \%$ more likely in children aged $4-5$ years than those aged $0-1$ year, but $51 \%$ less likely among children aged 6-8 years (table 3 ). Inclusion of Aboriginality and age as an interaction term in the model revealed that significant differences in procedure rates between Aboriginal and non-Aboriginal children lay in the $0-1$ and 2-3 years age group (figure 3A). Adjustment for significant covariates accounted for these gaps in receipt of procedures among the younger age groups (figure 3B). However, after differences in socioeconomic status and remoteness were taken into account, Aboriginal children aged 6-8 years had a higher likelihood of procedures than their same age non-Aboriginal peers. Other characteristics associated with an increased likelihood of receiving ventilation tubes in all children included: male sex, low birth weight, premature birth, being a private patient or having private health insurance, living in inner regional areas and living in more socioeconomically advantaged areas (table 3). Although children living in remote areas were less likely to receive ventilation tubes than children living in major cities in the unadjusted model, this difference was not significant after adjusting for indicators of socioeconomic status (table 3).

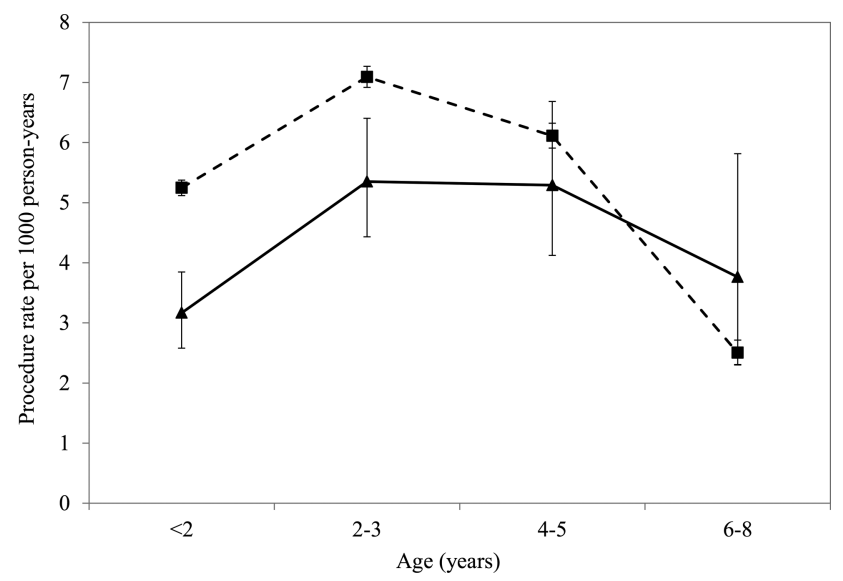

Figure 1 First ventilation tube insertion procedure rates in a cohort of children in New South Wales, Australia, 2000-2008, by Aboriginality and age. Legend: dashed line represents non-Aboriginal children; solid lines represent Aboriginal children.

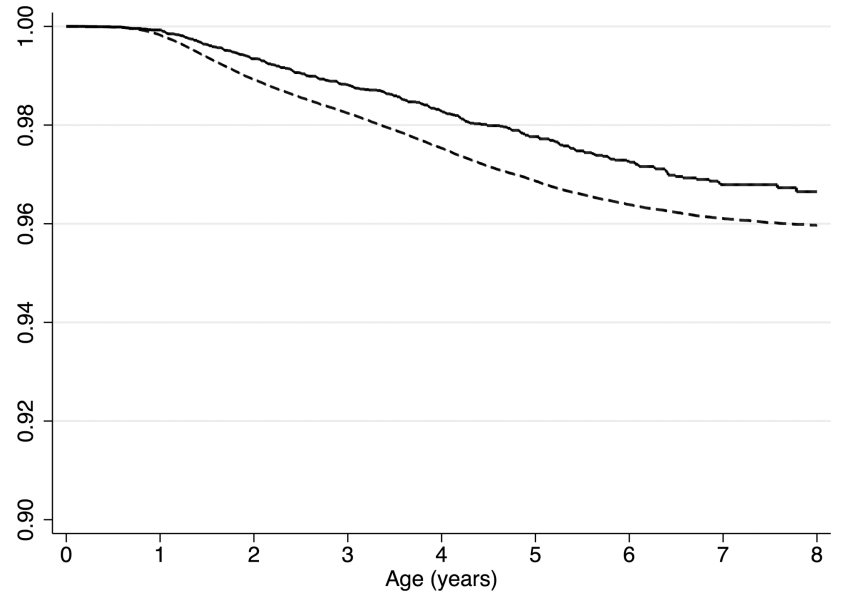

Figure 2 Time to first ventilation tube insertion in a cohort of children in New South Wales, Australia, 2000-08, by Aboriginality. Legend: dashed line represents non-Aboriginal children; solid lines represent Aboriginal children.

\section{Sensitivity analysis}

A total of 18714 (2.9\%) children were recorded as Aboriginal on their most recent hospital admission and 20575 (3.2\%) children were ever recorded as Aboriginal (data not shown). Of these, 431 and 568 had their first VTI procedure during the study period when using Aboriginal status from the most recent hospital record and any hospital record, respectively. Aboriginal children were less likely to have ventilation tubes inserted than non-Aboriginal children when Aboriginal status was obtained from the most recent hospital record (unadjusted RR 0.88 ; $95 \%$ CI 0.80 to 0.97 ); however, the difference was non-significant when Aboriginality from any hospital recorded was used (unadjusted RR 1.05; 95\% CI 0.96 to 1.14 ).

\section{DISCUSSION}

Our study identified significant inequality in the receipt of VTI procedures between Aboriginal and non-Aboriginal children in NSW. We found that VTI rates in Aboriginal children aged less than 4 years were approximately two-thirds of those in their same age non-Aboriginal peers. This finding is consistent with the inequality in first VTI procedure rates between Aboriginal and non-Aboriginal children aged 5 years or less in Western Australia in 1981$2004 .^{23}$ Although our study showed that this gap narrowed in children aged 5 years and over, Aboriginal children did not 'catch up' in terms of the proportion that had ventilation tubes inserted by their eighth birthday. The likelihood of having ventilation tubes inserted increased with increasing socioeconomic advantage and was higher for children living in major cities compared with remote areas. Our multivariate analyses showed that socioeconomic factors and-to a lesser extent-geographical remoteness largely explain the inequality in VTI procedures between Aboriginal and non-Aboriginal children in NSW. 
Table 2 Rate ratios for first ventilation tube insertion procedures in Aboriginal compared with non-Aboriginal children in a cohort of children in New South Wales, Australia, 2000-2008, including stepwise adjustment for covariates

\begin{tabular}{|c|c|c|c|c|}
\hline Model & Adjusted for & Rate ratio & $95 \% \mathrm{Cl}$ & p Value \\
\hline 1 & Null model & 0.72 & 0.64 to 0.80 & $<0.001$ \\
\hline 2 & Age and sex & 0.72 & 0.64 to 0.80 & $<0.001$ \\
\hline 3 & Age, sex, low birth weight & 0.71 & 0.63 to 0.79 & $<0.001$ \\
\hline 4 & Age, sex, prematurity & 0.71 & 0.63 to 0.79 & $<0.001$ \\
\hline 5 & Age, sex, private health insurance/patient & 0.96 & 0.86 to 1.08 & 0.532 \\
\hline 6 & Age, sex, geographical remoteness & 0.81 & 0.73 to 0.91 & $<0.001$ \\
\hline 7 & Age, sex, socioeconomic status* & 0.93 & 0.83 to 1.04 & 0.194 \\
\hline 8 & $\begin{array}{l}\text { Age, sex, low birth weight, prematurity, private } \\
\text { patient/insurance, geographical remoteness, socioeconomic status* }\end{array}$ & 1.06 & 0.94 to 1.19 & 0.321 \\
\hline
\end{tabular}

*Socioeconomic indices for Areas (SEIFA) Index of Relative Socio-Economic Advantage and Disadvantage based on statistical local area of residence at birth.

A key question is not so much what underlies the difference in VTI rates between Aboriginal and non-Aboriginal children, but whether procedures are provided relative to clinical need and according to clinical guidelines in both groups. Studies have consistently reported a higher burden of otitis media among Aboriginal children, ${ }^{8} 3031$ which suggests a higher overall need for intervention. However, the recommended hearing loss threshold for VTI procedures is higher in children at high risk of chronic suppurative otitis media because of the greater risk of infection associated with the procedure in these children. ${ }^{1920}$ There is currently limited information about the incidence, clinical course and severity of otitis media in Aboriginal

Table 3 Unadjusted and adjusted RRs for first VTI procedures in a cohort of children in New South Wales, Australia, 2000-2008

\begin{tabular}{|c|c|c|c|c|c|c|}
\hline & Unadjusted RR & $95 \% \mathrm{Cl}$ & $p$ value & Adjusted RR* & $95 \% \mathrm{Cl}$ & $p$ value \\
\hline \multicolumn{7}{|l|}{ Age (years) } \\
\hline$<2$ & 1.00 & & \multirow[t]{4}{*}{$<0.001$} & 1.00 & & \multirow[t]{4}{*}{$<0.001$} \\
\hline 2 to $<4$ & 1.36 & 1.31 to 1.40 & & 1.37 & 1.31 to 1.40 & \\
\hline 4 to $<6$ & 1.17 & 1.12 to 1.22 & & 1.18 & 1.12 to 1.22 & \\
\hline 6 to 8 & 0.49 & 0.45 to 0.53 & & 0.50 & 0.45 to 0.53 & \\
\hline \multicolumn{7}{|l|}{ Sex } \\
\hline Female & 1.00 & & \multirow[t]{2}{*}{$<0.001$} & 1.00 & & \multirow[t]{2}{*}{$<0.001$} \\
\hline Male & 1.54 & 1.49 to 1.59 & & 1.54 & 1.49 to 1.59 & \\
\hline \multicolumn{7}{|l|}{ Low birth weight } \\
\hline No & 1.00 & & \multirow[t]{2}{*}{$<0.001$} & 1.00 & & \multirow[t]{2}{*}{0.005} \\
\hline Yes & 1.32 & 1.22 to 1.42 & & 1.15 & 1.04 to 1.27 & \\
\hline \multicolumn{7}{|l|}{ Prematurity } \\
\hline No & 1.00 & & \multirow[t]{2}{*}{$<0.001$} & 1.00 & & \multirow[t]{2}{*}{$<0.001$} \\
\hline Yes & 1.34 & 1.26 to 1.41 & & 1.19 & 1.10 to 1.28 & \\
\hline \multicolumn{7}{|l|}{ Private patient or insurance } \\
\hline No & 1.00 & & \multirow[t]{2}{*}{$<0.001$} & 1.00 & & \multirow[t]{2}{*}{$<0.001$} \\
\hline Yes & 2.30 & 2.23 to 2.37 & & 1.97 & 1.91 to 2.03 & \\
\hline \multicolumn{7}{|c|}{ Geographical remoteness (ARIA+) } \\
\hline Major city & 1.00 & & \multirow[t]{4}{*}{$<0.001$} & 1.00 & & \multirow[t]{4}{*}{$<0.001$} \\
\hline Inner regional & 0.97 & 0.93 to 1.00 & & 1.15 & 1.11 to 1.20 & \\
\hline Outer regional & 0.60 & 0.56 to 0.64 & & 0.97 & 0.90 to 1.05 & \\
\hline Remote/very remote & 0.56 & 0.47 to 0.68 & & 0.89 & 0.73 to 1.09 & \\
\hline \multicolumn{7}{|l|}{ Area socioeconomic status $†$} \\
\hline First (most disadvantaged) & 1.00 & & \multirow[t]{5}{*}{$<0.001$} & 1.00 & & \multirow[t]{5}{*}{$<0.001$} \\
\hline Second & 1.46 & 1.38 to 1.54 & & 1.32 & 1.25 to 1.40 & \\
\hline Third & 1.41 & 1.33 to 1.49 & & 1.22 & 1.15 to 1.30 & \\
\hline Fourth & 1.62 & 1.54 to 1.71 & & 1.33 & 1.25 to 1.42 & \\
\hline Fifth (least disadvantaged) & 2.74 & 2.61 to 2.89 & & 1.95 & 1.83 to 2.07 & \\
\hline
\end{tabular}

${ }^{*}$ Adjusted for all significant covariates in the final multivariate model.

†SEIFA Index of Relative Socio-Economic Advantage and Disadvantage based on the child's statistical local area of residence at birth.

ARIA+, Accessibility/Remoteness Index of Australia; SEIFA, socio-economic indices for Areas; RR, rate ratio; VTI, ventilation tube insertion. 

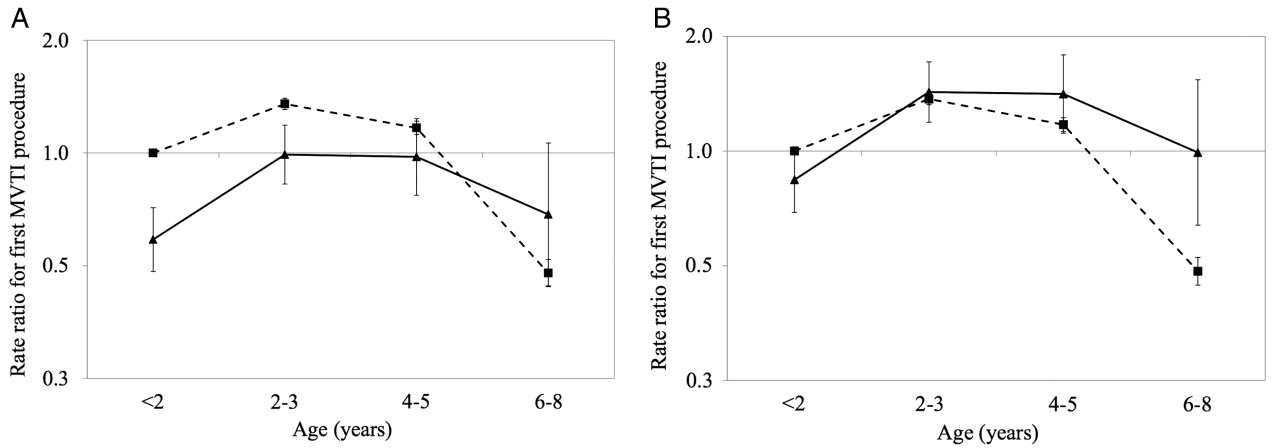

Figure 3 Rate ratios for first ventilation tube insertion procedures in a cohort of children in New South Wales, Australia, 2000-2008, by Aboriginality and age $\mathrm{a}^{\mathrm{a}}$ (A) adjusted for age and sex, and (B) adjusted for age, sex and significant mediating factors $^{\mathrm{b}}$. Legend: dashed line represents non-Aboriginal children; solid lines represent Aboriginal children. $\mathrm{a}$. Including an interaction term for Aboriginality and age. b. Significant mediating factors included in the final multivariate model: low birth weight, prematurity, private health insurance/patient, geographical remoteness and area socioeconomic status.

children, particularly in urban areas. Clinical research shows that Aboriginal children are more likely to suffer otitis media with effusion and acute otitis media during early infancy, ${ }^{32}$ and present with more severe and chronic otitis media than non-Aboriginal children. ${ }^{8}$ Furthermore, Aboriginal children are more prone to developing chronic suppurative otitis media. ${ }^{18}$ We were unable to ascertain the degree of hearing loss or obtain information on the clinical management of otitis media prior to surgery from our data, although results suggest a delay in the age at which procedures are performed in Aboriginal children. Despite this, it is unlikely that the large inequality in VTI procedures in our study can be appropriately explained by more prevalent chronic suppurative otitis media in Aboriginal children alone. Furthermore, inequalities in the prevalence of chronic suppurative otitis media may reflect issues such as late diagnosis and less access to health services in remote areas.

Our finding that VTI rates increased with increasing socioeconomic advantage is consistent with those of another Australian study ${ }^{23}$ and studies from Europe and North America. ${ }^{33-37}$ Similar patterns of inequality have also been found with 'discretionary' procedures in the Australian adult population. ${ }^{38}{ }^{39}$ In our study, the socioeconomic gradient was evident in Aboriginal and non-Aboriginal children. The important difference between the two groups is that socioeconomic disadvantage disproportionately affects Aboriginal children. Adjustment for socioeconomic factors in our multivariate analysis reduced inequalities in the receipt of procedures, and the inequality was no longer significant. We now consider at least three potential mechanisms by which socioeconomic advantage might increase a child's chance of having ventilation tubes inserted.

First, it is possible that higher participation in formal child care-which has been associated with otitis media and the carriage of related pathogens ${ }^{10} 34{ }^{40}$-among more socioeconomically advantaged children ${ }^{41}$ is one factor that might increase the incidence of otitis media among these children and thereby their clinical need for procedures. Child-care participation could not be ascertained from our data, and therefore we were unable to estimate to what extent this might explain the socioeconomic gradient in procedures.

A second and more probable mechanism is that socioeconomically advantaged children have better access to health services. Children with otitis media may gain access to specialist ear health services via financial means, such as private health insurance. Our data support this, as do the findings from a North American study. ${ }^{34}$ Better access to specialist ear health services is also influenced by the availability of audiologists and ear, nose and throat (ENT) surgeons in the area where a child lives, with affluent families more commonly living in areas with a greater supply of hospital-based and private specialist services. ${ }^{42}$ Parental education might also play a role in the parent's ability to effectively navigate our complex health system to gain access to specialist services on their child's behalf.

A third factor that may contribute towards higher procedure rates among more socioeconomically advantaged children is the overuse of procedures. There is no published evaluation of this in Australia; however, a significant discrepancy between the insertion of ventilation tubes and clinical guidelines was reported among New York metropolitan hospitals in the USA ${ }^{43}$ The most common discrepancy between guidelines and practice was the premature insertion of ventilation tubes. ${ }^{43}$ However, even among the most advantaged children in our cohort, the proportion who had a ventilation tube inserted by 8 years of age (6\%; data not shown) was lower than that in studies from the $\mathrm{USA}^{34}$ and Europe. $^{44} 45$ This may reflect differences in incident otitis media, clinical guidelines and guideline adherence, as well as lesser availability of ENT surgeons in the Australian setting. ${ }^{46} 47$

Despite the high burden of otitis media in Aboriginal children living in remote Australian communities ${ }^{2} 8$ 48-50 and children attending remote Aboriginal Medical 
Services nationally, ${ }^{42}$ we found lower VTI rates among Aboriginal compared with non-Aboriginal children in remote areas in NSW. Furthermore, our analyses indicate that remoteness was a significant mediating factor in the relationship between Aboriginality and the insertion of ventilation tubes. Similar to other states, Aboriginal children are disproportionately affected by remoteness in NSW. ${ }^{26}$ The disparate and less frequently available nature of specialist ear health services in remote areas $^{42}$ is likely to account for much of the inequalities in the receipt of procedures between children living in remote areas and major cities. It does not, however, explain the inequalities between Aboriginal and non-Aboriginal children living in remote areas. One possibility is that Aboriginal children living in remote communities represent some of the most socioeconomically disadvantaged children in the state. These children are likely to face multiple-and interrelatedbarriers to accessing health services. Aside from private patient or health insurance status, we were unable to ascertain other individual-level indicators of socioeconomic status (eg, household income, parental employment) or disadvantage (eg, single parent family, child placed in out-of-home care) from our data. Another possibility is that ENT surgeons may be reluctant to insert ventilation tubes in Aboriginal children who live in remote areas because of the challenges in providing postoperative follow-up. It is also plausible that parental acceptance of otitis media as the norm in remote Aboriginal families means they may be less likely to seek treatment.

Our study's greatest strength was its use of a whole-of-population cohort, which maximised statistical power and minimised bias associated with participant selection. Although an unknown number of children were lost to follow-up through migration, children account for a small proportion of the $3 \%$ of the NSW population who migrate annually. ${ }^{51} 52$ Other strengths of this study include the extended follow-up and excellent capture of surgical procedures in administrative hospital data. ${ }^{17}$ The large size of our cohort, together with the geographical diversity and the distribution of Aboriginal children across metropolitan, regional and remote areas, not only enabled us to quantify the inequality in VTI procedures between Aboriginal and non-Aboriginal children, but also to investigate-for the first time in Australia-the influence of factors such as remoteness and socioeconomic background on this inequality.

Some limitations in the source data must be considered in interpreting our findings. The first is that Aboriginal people are under-recorded in the NSW hospital data. ${ }^{27}{ }^{53-55}$ Furthermore, these recording errors are not randomly distributed. For example, hospitals in remote areas have a more accurate recording of Aboriginal status than hospitals in major cities. ${ }^{27}{ }^{54}$ Since we used a cohort approach in our study, under-recording will have affected the numerator and denominator, as opposed to the numerator only, which is the case when population rates are estimated using census data as the denominator. For this reason, our study would have been less sensitive to an underrecording of Aboriginal status. Audits of hospital data have also shown that the recording of Aboriginality has improved over time. ${ }^{27} 54$ Although there was some variation in procedure rates among Aboriginal children during the study period, we found no significant trend over time. We used Aboriginal status from children's birth records to minimise differential misclassification bias relating to the number and recency of hospital admissions.

Another shortcoming of our study is that we were unable to obtain an updated area of residence for children who were not admitted to hospital since their birth admission. To avoid introducing differential misclassification bias for geographical remoteness and area-level socioeconomic status, we used the area of residence at birth for all children in our analyses. Among children who had ventilation tubes inserted, the proportions that changed the remoteness category or socioeconomic quintile between their birth and procedure admission were $6 \%$ and $11 \%$, respectively.

We were limited to two indicators of socioeconomic status in our analyses, of which private patient/health insurance status was an individual-level variable. The use of area-based measures such as the SEIFA Index of Relative Socio-economic Advantage and Disadvantage has the potential to introduce ecological fallacy. In related research, area-level socioeconomic status has been associated with the community prevalence of otitis media in North America. ${ }^{56}$ Our findings that adjustment for either the individual-level or area-level socioeconomic variable in our model had a similar effect in direction and quantity suggests that both were reasonable indicators of socioeconomic status in this large cohort.

In 2008, the Council of Australian Governments committed to reducing Indigenous disadvantage and set six targets to 'Close the Gap' between Aboriginal and non-Aboriginal people. ${ }^{57}$ This included halving the gap in numeracy and literacy outcomes between Aboriginal and non-Aboriginal children by $2018 .{ }^{57}$ Despite the political will, progress towards these targets has been disappointing. ${ }^{58}$ Until the early childhood health and developmental inequalities are reduced, it is most likely that the education outcomes and life prospects of many Aboriginal children will remain poor. Otitis media is an important early childhood health condition that can affect hearing, speech and language development. ${ }^{59-61}$ Our findings suggest that Aboriginal children may face barriers to accessing appropriate care for otitis media, as well as the possible overuse of procedures among advantaged children. However, many questions remain unanswered. This study highlights the need for stronger evidence regarding the prevalence, severity and clinical course of otitis media in Australian Aboriginal children, and the appropriateness of care received. 
Author affiliations

${ }^{1}$ National Centre for Epidemiology and Population Health, The Australian National University, Canberra, Australia

${ }^{2}$ The Sax Institute, Sydney, Australia

${ }^{3}$ Centre for Health Research, School of Medicine, University of Western Sydney, Campbelltown, Australia

${ }^{4}$ School of Public Health, University of Sydney, Sydney, Australia

${ }^{5}$ Department of General Medicine, The Children's Hospital at Westmead, Westmead, Australia

${ }^{6}$ School of Medicine, University of Western Sydney, Campbelltown, Australia

Acknowledgements The authors would like to acknowledge the New South Wales (NSW) Ministry of Health and the NSW Register of Births, Deaths and Marriages for allowing access to the data, and the Centre for Health Record Linkage for conducting the probabilistic linkage of records. The authors also acknowledge the participation of Dr Hilary Bambrick, Dr Brigette McNamara and Dr Kristjana Einarsdottir in the discussion of the preliminary results of this study in September 2010

Contributors LJ and SE contributed to the conception and design of the Indigenous Health Outcomes Patient Evaluation (IHOPE) study. LJ initiated the IHOPE study and provided oversight for all analyses. DR coordinated the IHOPE study and was responsible for the management and preparation of the IHOPE dataset, and provided advice on the data preparation and statistical aspects of this substudy. KF designed and conducted the statistical analysis for this substudy, prepared the IHOPE birth cohort dataset and drafted the manuscript. All authors contributed to the interpretation of findings, provided feedback on drafts of the manuscript and approved the final draft.

Funding This work was supported by the National Health and Medical Research Council (NHMRC; grant number 573113). KF was supported by an NHMRC Early Career Fellowship (\#1016475) and an NHMRC capacity building grant (\#573122). EB was supported by an NHMRC Senior Research Fellowship (\#1042717).

\section{Competing interests None.}

Ethics approval NSW Population and Health Services Research Ethics Committee; the Aboriginal Health and Medical Research Council of NSW Ethics Committee; and the University of Western Sydney Human Research Ethics Committee.

Provenance and peer review Not commissioned; externally peer reviewed.

Data sharing statement This study used linked hospital and mortality records in NSW, Australia. These data are available to researchers on request and subject to approval from the relevant data custodians and ethics committees, as outlined on the NSW Centre for Health Record Linkage website (http://www.cherel.org.au)

Open Access This is an Open Access article distributed in accordance with the Creative Commons Attribution Non Commercial (CC BY-NC 3.0) license, which permits others to distribute, remix, adapt, build upon this work noncommercially, and license their derivative works on different terms, provided the original work is properly cited and the use is non-commercial. See: http:// creativecommons.org/licenses/by-nc/3.0/

\section{REFERENCES}

1. Morris PS, Leach AJ, Halpin S, et al. An overview of acute otitis media in Australian Aboriginal children living in remote communities. Vaccine 2007;25:2389-93.

2. Morris PS, Leach AJ, Silberberg $P$, et al. Otitis media in young Aboriginal children from remote communities in Northern and Centra Australia: a cross-sectional survey. BMC Pediatr 2005;5:27.

3. Australian Institute of Health and Welfare and Department of Health and Ageing. Progress of the northern territory emergency response child health check initiative: preliminary results from the child health check and follow-up data collections. Cat. no. IHW 25. Canberra: Australian Institute of Health and Welfare and Department of Health and Ageing, 2008.

4. World Health Organisation. Chronic suppurative otitis media. Burden of illness and management options. Geneva, Switzerland: World Health Organisation, 2004
5. Williams CJ, Coates HL, Pascoe EM, et al. Middle ear disease in Aboriginal children in Perth: analysis of hearing screening data 1998-2004. Med J Aust 2009;190:598-600.

6. Australian Bureau of Statistics. Population distribution Aboriginal and Torres Strait Islander Australians, 2006. ABS Catalogue No. 4705.0. Canberra: Australian Bureau of Statistics, 2007.

7. Australian Bureau of Statistics. National Aboriginal and Torres Strait Islander Health Survey 2004-05. ABS Catalogue No. 4715.0. Canberra: Australian Bureau of Statistics, 2006.

8. Boswell JB, Nienhuys TG. Patterns of persistent otitis media in the first year of life in aboriginal and non-aboriginal infants. Ann Otol Rhinol Laryngol 1996;105:893-900.

9. Gunasekera $\mathrm{H}$, Knox S, Morris $\mathrm{P}$, et al. The spectrum and management of otitis media in Australian indigenous and non-indigenous children. Pediatr Infect Dis J 2007;26:689-92.

10. Jacoby $\mathrm{P}$, Carville KS, Hall G, et al. Crowding and other strong predictors of upper respiratory tract carriage of otitis media-related bacteria in Australian aboriginal and non-aboriginal children. Pediatr Infect Dis J 2011;30:480-5.

11. Jacoby PA, Coates HL, Arumugaswamy A, et al. The effect of passive smoking on the risk of otitis media in Aboriginal and non-Aboriginal children in the Kalgoorlie-Boulder region of Western Australia. Med J Aust 2008;188:599-603.

12. Skull SA, Morris PS, Yonovitz A, et al. Middle ear effusion: rate and risk factors in Australian children attending day care. Epidemiol Infect 1999;123:57-64.

13. Teele DW, Klein JO, Rosner B. Epidemiology of otitis media during the first seven years of life in children in greater Boston: a prospective, cohort study. J Infect Dis 1989;160:83-94.

14. Shepherd CC, Li J, Zubrick SR. Socioeconomic disparities in physical health among Aboriginal and Torres Strait Islander children in Western Australia. Ethn Health 2012;17:439-61.

15. Gibson PG, Stuart JE, Wlodarczyk J, et al. Nasal inflammation and chronic ear disease in Australian Aboriginal children. J Paediatr Child Health 1996;32:143-7.

16. Smith-Vaughan $\mathrm{H}$, Byun $\mathrm{R}$, Nadkarni $\mathrm{M}$, et al. Measuring nasal bacterial load and its association with otitis media. BMC Ear Nose Throat Disord 2006;6:10.

17. Henderson T, Shepheard J, Sundararajan V. Quality of diagnosis and procedure coding in ICD-10 administrative data. Med Care 2006;44:1011-19.

18. Darwin Otitis Media Guidelines Group in collaboration with the Office for Aboriginal and Torres Strait Islander Health Otitis Media Technical Advisory Group. Recommendations for clinical care guidelines on the management of otitis media in Aboriginal and Torres Strait Islander Populations. Canberra: Australian Government Department of Health and Ageing, 2010.

19. Gunasekera H, O'Connor TE, Vijayasekaran S, et al. Primary care management of otitis media among Australian children. Med J Aust 2009;191:S55-9.

20. Morris $\mathrm{P}$, Ballinger D, Leach A, et al. Recommendations for clinical care guidelines on the management of otitis media in Aboriginal and Torres Strait Islander Populations. Canberra: Office for Aborigina and Torres Strait Islander Health, Commonwealth Department of Health and Aged Care, 2001

21. Lous J, Burton MJ, Felding JU, et al. Grommets (ventilation tubes) for hearing loss associated with otitis media with effusion in children. Cochrane Database Syst Rev 2005;(1):CD001801.

22. McDonald S, Langton Hewer CD, Nunez DA. Grommets (ventilation tubes) for recurrent acute otitis media in children. Cochrane Database Syst Rev 2008;(4):CD004741.

23. Spilsbury K, Kadhim AL, Semmens JB, et al. Decreasing rates of middle ear surgery in Western Australian children. Arch Otolaryngol Head Neck Surg 2006;132:1216-20.

24. National Centre for Classification in Health. International Statistical Classification of Diseases and Related Health Problems, 10th Revision, Australian Modification (ICD-10-AM), Australian Classification of Health Interventions (ACHI) and Australian Coding Standards (ACS). Sydney, Australia: National Centre for Classification in Health, 2006.

25. Centre for Health Record Linkage. Secondary. http://www.cherel.org.au

26. Australian Bureau of Statistics. Population characteristics, Aboriginal and Torres Strait Islander Australians. ABS Catalogue No. 4713.0. Canberra: Australian Bureau of Statistics, 2006.

27. Australian Institute of Health and Welfare. Indigenous identification in hospital separations data-quality report. Health Services Series no. 35. Cat no. HSE 85. Canberra: Australian Institute of Health and Welfare, 2010

28. Australian Bureau of Statistics. Australian Standard Geographical Classification (ASGC) Remoteness Classification: Purpose and Use. Census Paper No. 03/01. Canberra: Australian Bureau of Statistics, 2003. 
29. Australian Bureau of Statistics. Socio-Economic Indexes for Area (SEIFA)-Technical Paper 2006. Canberra, Australia: Australian Bureau of Statistics, 2008.

30. Lehmann D, Arumugaswamy A, Elsbury D, et al. The Kalgoorlie Otitis Media Research Project: rationale, methods, population characteristics and ethical considerations. Paediatr Perinat Epidemiol 2008;22:60-71.

31. Torzillo PJ, Waterford JE, Hollows FC, et al. Respiratory disease amongst Aborigines in the Pilbara. Int J Epidemiol 1983;12:105-6.

32. Boswell JB, Nienhuys TG. Onset of otitis media in the first eight weeks of life in aboriginal and non-aboriginal Australian infants. Ann Otol Rhinol Laryngol 1995;104:542-9.

33. Croxford R, Friedberg J, Coyte PC. Socio-economic status and surgery in children: myringotomies and tonsillectomies in Ontario, Canada, 1996-2000. Acta Paediatr 2004;93:1245-50.

34. Kogan MD, Overpeck MD, Hoffman HJ, et al. Factors associated with tympanostomy tube insertion among preschool-aged children in the United States. Am J Public Health 2000;90:245-50.

35. Lous J, Friis K, Vinding AL, et al. Social marginalization reduces use of ENT physicians in primary care. Int $\mathrm{J}$ Pediatr Otorhinolaryngol 2012;76:370-3.

36. Smith DF, Boss EF. Racial/ethnic and socioeconomic disparities in the prevalence and treatment of otitis media in children in the United States. Laryngoscope 2010;120:2306-12

37. Vakharia KT, Shapiro NL, Bhattacharyya N. Demographic disparities among children with frequent ear infections in the United States. Laryngoscope 2010;120:1667-70.

38. Korda RJ, Clements MS, Kelman CW. Universal health care no guarantee of equity: comparison of socioeconomic inequalities in the receipt of coronary procedures in patients with acute myocardial infarction and angina. BMC Public Health 2009;9:460.

39. Korda RJ, Joshy G, Jorm LR, et al. Inequalities in bariatric surgery in Australia: findings from 49,364 obese participants in a prospective cohort study. Med J Aust 2012;197:631-6.

40. Bailie R, Stevens M, McDonald E, et al. Exploring cross-sectional associations between common childhood illness, housing and social conditions in remote Australian Aboriginal communities. BMC Public Health 2010;10:147.

41. Australian Bureau of Statistics. Childhood Education and Care Australia, Datacubes, June 2011-New South Wales. ABS Catalogue No. 4402.0.55.003. Canberra: Australian Bureau of Statistics, 2011.

42. Gunasekera H, Morris PS, Daniels J, et al. Otitis media in Aboriginal children: the discordance between burden of illness and access to services in rural/remote and urban Australia. $J$ Paediatr Child Health 2009;45:425-30.

43. Keyhani S, Kleinman LC, Rothschild M, et al. Overuse of tympanostomy tubes in New York metropolitan area: evidence from five hospital cohort. BMJ 2008;337:a1607.

44. Arason VA, Sigurdsson JA, Kristinsson KG, et al. Otitis media, tympanostomy tube placement, and use of antibiotics. Cross-sectiona community study repeated after five years. Scand J Prim Health Care 2005;23:184-91.

45. Lok W, Chenault MN, Anteunis LJ. Implementation of neonatal screening for hearing impairment: influence on pediatric otitis media surgery in The Netherlands. Int J Pediatr Otorhinolaryngol 2009;73:1090-4.

46. Australian Medical Workforce Advisory Committee. The Ear, Nose and Throat Surgery Workforce In Australia, AMWAC Report 1997.6. Sydney, 1997.

47. Kim JSC, Cooper RA, Kennedy DW. Otolaryngology-head and neck surgery physician work force issues: an analysis for future specialty planning. Otolaryngol Head Neck Surg 2012;146:196-202.

48. Kelly HA, Weeks SA. Ear disease in three aboriginal communities in Western Australia. Med J Aust 1991;154:240-5.

49. Oddy WH, Kickett-Tucker C, De Maio J, et al. The association of infant feeding with parent-reported infections and hospitalisations in the West Australian Aboriginal Child Health Survey. Aust N Z J Public Health 2008;32:207-15.

50. Zubrick S, Lawrence D, Silburn S, et al. The Western Australian Aboriginal Child Health Survey: the health of Aboriginal children and young people. Perth: Telethon Institute for Child Health Research, 2004.

51. Australian Bureau of Statistics. Migration 2010-11. ABS Catalogue No. 3412.0. Canberra: Australian Bureau of Statistics, 2012.

52. Australian Bureau of Statistics. Australian Demographic Statistics. ABS Catalogue No. 3101.0 Table 4. Estimated Resident Population, States and Territories. Canberra: Australian Bureau of Statistics, 2012.

53. Australian Institute of Health and Welfare. Improving the quality of Indigenous identification in hospital separations data. AlHW cat. no. HSE 101. Canberra: Australian Institute of Health and Welfare, 2005.

54. Bentley JP, Taylor LK, Brandt PG. Reporting of Aboriginal and Torres Strait Islander peoples on the NSW Admitted Patient Data Collection: the 2010 data quality survey. N S W Public Health Bull 2012;23:17-20.

55. Neville SE, Taylor LK, Moore $\mathrm{H}$, et al. Using linkage between hospital and ABS mortality data to enhance reporting of deaths among Aboriginal and Torres Strait Islander peoples. Aust N Z J Public Health 2011;35:543-8.

56. Hudson HM, Rockett IR. An environmental and demographic analysis of otitis media in rural Australian aborigines. Int $J$ Epidemiol 1984;13:73-82.

57. Department of Families Housing Community Services and Indigenous Affairs. Closing the gap: Prime Minister's report 2010. Canberra: Department of Families, Housing, Community Services and Indigenous affairs, 2010.

58. Department of Families Housing Community Services and Indigenous Affairs. Closing the gap: Prime Minister's report 2013. Canberra: Department of Families, Housing, Community Services and Indigenous affairs, 2013.

59. Roberts J, Hunter L, Gravel J, et al. Otitis media, hearing loss, and language learning: controversies and current research. J Dev Behav Pediatr 2004;25:110-22.

60. Roberts JE, Rosenfeld RM, Zeisel SA. Otitis media and speech and language: a meta-analysis of prospective studies. Pediatrics 2004;113:e238-48.

61. Williams CJ, Jacobs AM. The impact of otitis media on cognitive and educational outcomes. Med J Aust 2009;191:S69-72. 